\title{
Biomarkers for Radiation Pneumonitis Using Noninvasive Molecular Imaging
}

\author{
Meetha Medhora ${ }^{1-5}$, Steven Haworth ${ }^{2,5}$, Yu Liu ${ }^{6}$, Jayashree Narayanan ${ }^{1}$, Feng Gao ${ }^{1}$, Ming Zhao ${ }^{7}$, Said Audi $^{2,5,8}$, \\ Elizabeth R. Jacobs ${ }^{2-5}$, Brian L. Fish ${ }^{1}$, and Anne V. Clough ${ }^{2,5,9}$ \\ ${ }^{1}$ Department of Radiation Oncology, Medical College of Wisconsin, Milwaukee, Wisconsin; ${ }^{2}$ Department of Medicine, Medical \\ College of Wisconsin, Milwaukee, Wisconsin; ${ }^{3}$ Department of Physiology, Medical College of Wisconsin, Milwaukee, Wisconsin; \\ ${ }^{4}$ Cardiovascular Center, Medical College of Wisconsin, Milwaukee, Wisconsin; ${ }^{5}$ Research Service, Zablocki Veterans Affairs Medical \\ Center, Milwaukee, Wisconsin; ${ }^{6}$ Center for Imaging Research, Medical College of Wisconsin, Milwaukee, Wisconsin; ${ }^{7}$ Department \\ of Medicine, Feinberg School of Medicine, Northwestern University, Chicago, Illinois; ${ }^{8}$ Department of Biomedical Engineering, \\ Marquette University, Milwaukee, Wisconsin; and ${ }^{9}$ Department of Mathematics, Statistics and Computer Science, Marquette \\ University, Milwaukee, Wisconsin
}

Our goal is to develop minimally invasive biomarkers for predicting radiation-induced lung injury before symptoms develop. Currently, there are no biomarkers that can predict radiation pneumonitis. Radiation damage to the whole lung is a serious risk in nuclear accidents or in radiologic terrorism. Our previous studies have shown that a single dose of 15 Gy of $\mathrm{x}$-rays to the thorax causes severe pneumonitis in rats by $6-$ $8 \mathrm{wk}$. We have also developed a mitigator for radiation pneumonitis and fibrosis that can be started as late as $5 \mathrm{wk}$ after radiation. Methods: We used 2 functional SPECT probes in vivo in irradiated rat lungs. Regional pulmonary perfusion was measured by injection of $99 \mathrm{mTc}$-macroaggregated albumin. Perfused volume was determined by comparing the volume of distribution of ${ }^{99 \mathrm{mTc}-m a c r o a g g r e g a t e d ~ a l b u m i n}$ to the anatomic lung volume obtained by small-animal CT. A second probe, 99mTc-labeled Duramycin, which binds to apoptotic cells, was used to measure pulmonary cell death in the same rat model. Results: The perfused volume of lung was decreased by about $25 \%$ at 1,2 , and 3 wk after receipt of $15 \mathrm{~Gy}$, and ${ }^{99 \mathrm{~m} T c-D u r a m y c i n ~ u p t a k e ~ w a s ~ m o r e ~ t h a n ~}$ doubled at 2 and 3 wk. There was no change in body weight, breathing rate, or lung histology between irradiated and nonirradiated rats at these times. Pulmonary vascular resistance and vascular permeability measured in isolated perfused lungs ex vivo increased at 2 wk after 15 Gy of irradiation. Conclusion: Our results suggest that SPECT biomarkers have the potential to predict radiation injury to the lungs before substantial functional or histologic damage is observed. Early prediction of radiation pneumonitis in time to initiate mitigation will benefit those exposed to radiation in the context of therapy, accidents, or terrorism.

Key Words: SPECT; radiation injury; lung perfusion; radiological

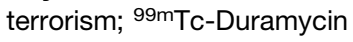

J Nucl Med 2016; 57:1296-1301

DOI: 10.2967/jnumed.115.160291

I njury by ionizing radiation to the lung manifests in two phases $(1,2)$. The first phase (pneumonitis) occurs 6-12 wk after irradiation.

Received May 13, 2015; revision accepted Jan. 21, 2016.

For correspondence or reprints contact: Meetha Medhora, MFRC 4076, Medical College of Wisconsin, 8701 Watertown Plank Rd., Milwaukee, WI 53226.

E-mail: medhoram@mcw.edu

Published online Mar. 31, 2016.

COPYRIGHT (C 2016 by the Society of Nuclear Medicine and Molecular Imaging, Inc.
The second phase (pulmonary fibrosis) develops over the months to years after exposure $(1,2)$. Our goal is to develop biomarkers that can predict severe lung injury before symptoms manifest and in time for mitigating agents to be applied. This goal is relevant to radiotherapy and to the National Institutes of Health program to develop countermeasures for nuclear accidents and radiologic terrorism. Using preclinical models, we have mitigated radiation pneumonitis and fibrosis with an angiotensin-converting enzyme inhibitor, enalapril, started 5 wk after irradiation (3). We are now developing noninvasive biomarkers to detect severe lung injury before this 5-wk time point.

Because there is a latent period between irradiation and symptoms of injury to the lung, biomarkers can be measured in this time to predict outcomes. Changes in regional perfusion by localized radiation but not to the whole lung have been detected by SPECT in vivo by injection of ${ }^{99 \mathrm{~m} T c-m a c r o a g g r e g a t e d ~ a l b u m i n ~(M A A) ~(4-7) . ~}$ The albumin is lodged within the intricate microvasculature of the lung in proportion to flow and detected by the $\gamma$-camera of the SPECT system. In general, perfusion redistribution from radiation is more frequently reported than ventilation defects $(4,8)$, and both are more sensitive than changes in lung density identified with CT (4).

A different SPECT probe, ${ }^{99 \mathrm{~m} T c-l a b e l e d ~ t e t r a c y c l i n e ~ h y d r o c h l o-~}$ ride (Duramycin; Durvet, Inc.), is known to have high affinity and specificity for phosphatidylethanolamine, which is externalized in apoptotic and other dying cells (9). Because radiation has been reported to induce apoptosis (10-12), necrosis, and mitotic cell death, this marker was used to assess whole-body tissue damage after radiation exposure (13). We tested the two probes ${ }^{99 m}$ Tc-MAA and ${ }^{99 \mathrm{~m}} \mathrm{Tc}$-Duramycin as candidate biomarkers to monitor injury to the lungs at 1-4 wk after irradiation. We followed our imaging studies with histologic evaluation and other methods to confirm and interpret our findings.

\section{MATERIALS AND METHODS}

\section{Animal Care}

All animal protocols and euthanasia criteria have been previously described $(3,14)$ and were approved by the Institutional Animal Care and Use Committee. A separate group of animals was used to measure each endpoint.

\section{Irradiation}

Unanesthetized female WAG/RijCmcr rats were irradiated with 15 Gy to only the thorax at 9-10 wk of age as previously described (15). 
They were studied for noninvasive or terminal endpoints $1,2,3$, and 4 wk after irradiation. Nonirradiated rats were not sham-irradiated but were of the same age, strain, and sex and maintained in parallel with each batch of irradiated rats.

\section{SPECT/CT}

MAA (Jubilant DraxImage) was labeled with ${ }^{99 \mathrm{~m}} \mathrm{Tc}$ according to the kit instructions, and Duramycin (3,035 g/mole molecular weight) was prepared and labeled as previously described $(16,17)$. One group was then administered a single dose of $24.6 \pm 3.9 \mathrm{MBq}$ (mean $\pm \mathrm{SD}$ ) of ${ }^{99 \mathrm{~m} T c-M A A}$ via the tail vein using a 25 -gauge catheter. Another group received a tail vein injection of $38.5 \pm 7.6 \mathrm{MBq}$ of ${ }^{99 \mathrm{~m}} \mathrm{Tc}-$ Duramycin. The animals were positioned in a SPECT/CT scanner (Triumph; TriFoil Imaging) and first underwent rapid CT scanning for anatomic localization. At $5 \mathrm{~min}$ (for rats given ${ }^{99 \mathrm{~m}} \mathrm{Tc}-\mathrm{MAA}$ ) or $50 \mathrm{~min}$ (for rats given ${ }^{99 \mathrm{~m}} \mathrm{Tc}$-Duramycin) after injection, that is, times for optimal lung uptake, in vivo radionuclide imaging was performed using multipinhole collimation with two $\gamma$-head detectors, a 130- to $150-\mathrm{keV}$ energy window, and acquisition of 72 projections for $10 \mathrm{~s}$ each. SPECT and CT data were reconstructed and coregistered using inbuilt software (13).

\section{Image Analysis}

The reconstructed CT and ${ }^{99 \mathrm{~m}} \mathrm{Tc}-\mathrm{MAA}$ image volumes were segmented and analyzed to determine the perfused lung volume as follows. First, the lung region within the CT image volume was identified as previously described (18). A grayscale window with a lower threshold of zero (corresponding to air) and an upper threshold of the maximum grayscale value within the lung parenchyma region, excluding major blood-filled vessels, was established and used to determine the boundaries of the anatomic lung region. The total number of voxels within this lung region was then scaled by the volume of each voxel to determine the anatomic lung volume. This region served as a binary lung mask that was then applied to the reconstructed ${ }^{99 \mathrm{~m}} \mathrm{Tc}-\mathrm{MAA}$ image volume. The total number of nonzero voxels within the ${ }^{99 \mathrm{~m}} \mathrm{Tc}-\mathrm{MAA}$ SPECT lung region was determined and scaled by the volume of each SPECT voxel to determine the perfused lung volume. Finally, the fraction of lung perfused was determined by dividing the perfused lung volume obtained from ${ }^{99 \mathrm{~m} T c-M A A}$ by the anatomic lung volume obtained from CT. Perfused fractions were infrequently greater than 1 , since the volume of a voxel differed between SPECT and CT.

For experiments involving ${ }^{99 \mathrm{~m}} \mathrm{Tc}-\mathrm{Duramycin}$, the reconstructed $\mathrm{CT}$ and SPECT image volumes were coregistered, and lung boundaries obtained from CT were applied as a mask to determine the ${ }^{99 \mathrm{~m}} \mathrm{Tc}$-Duramycin lung region as described for ${ }^{99 \mathrm{~m}} \mathrm{Tc}-\mathrm{MAA} .{ }^{99 \mathrm{~m}} \mathrm{Tc}$-Duramycin lung uptake was then determined as average ${ }^{99 \mathrm{~m}} \mathrm{Tc}$-Duramycin counts per voxel within the lung region normalized to injected dose $(16,17,19)$.

\section{Breathing Rate}

Breathing rates and body weights were measured serially in an independent group of rats as described previously $(14,20)$.

\section{Isolated Perfused Lung Preparation and Pulmonary Vascular Endothelial Filtration Coefficient $\left(K_{f}\right)$}

The heart and lungs from an independent group of rats were isolated at the 2-wk time point and suspended from a calibrated force displacement transducer (model FT03; Grass Instruments), and lung weight was monitored continuously as previously described (21). The lungs were perfused and ventilated (40 breaths/min) with end-inspiratory and end-expiratory pressures of about 8 and $4 \mathrm{~cm} \mathrm{H}_{2} \mathrm{O}$. The $K_{f}$ was determined using the approach described by Bongard et al. (22). The venous pressure was set at atmospheric pressure and then raised to $5 \mathrm{~cm} \mathrm{H}_{2} \mathrm{O}$ for $10 \mathrm{~min}$ and $13.5 \mathrm{~cm} \mathrm{H}_{2} \mathrm{O}$ for an additional $10 \mathrm{~min}$. At the end, the lungs were removed from the perfusion system, the arterial and venous cannulas connected, and the pressure drop in the cannulas
$\left(\Delta P_{c a n}\right)$ determined. The pulmonary vascular pressure, $R_{V}$, was then calculated using

$$
R_{v}=\frac{P_{a}-\Delta P_{c a n}}{F}
$$

where $P_{a}$ is the pulmonary arterial pressure measured at the end of the 10-min stabilization period with venous pressure set at $0 \mathrm{~mm} \mathrm{Hg}$, and $F$ is the pump flow rate $(0.03 \mathrm{~mL} / \mathrm{min} / \mathrm{g}$ of body weight $)$.

\section{Lung Wet/Dry Weight}

After the $K_{f}$ studies were completed, the lungs were weighed, dried at $60^{\circ} \mathrm{C}-80^{\circ} \mathrm{C}$ for $24 \mathrm{~h}$, and weighed again to calculate the wet and dry weights.

\section{Histology}

Whole-mount sections of the left lung were stained with hematoxylin and eosin (Richard-Allan), with antibodies to cleaved caspase 3 (CP229B; Biocare (17)) to detect apoptotic cells (23), or with CD68 (MCA341R; abD Serotec) to identify macrophages (24).

Histologic scores were obtained in hematoxylin- and eosin-stained lung sections for the following 4 endpoints, as previously described $(14,20)$ : vascular wall thickness, foamy macrophages, CD68 + macrophages, and alveolar wall thickness. Caspase 3-positive cells were counted as previously described (17), and CD68+ macrophages (24) were counted in 5 fields randomly selected from corresponding areas in each section to cover the whole mount.

\section{Statistical Analysis}

Data were analyzed using StatView (version 5.0.1; SAS Institute) and expressed as mean \pm SD or median $\pm 75 \%$ and $25 \%$ ranges if normality or equal variance tests failed. For some tests, the control values at 1 and $4 \mathrm{wk}$ were pooled if they were not statistically different. For multigroup comparisons, the significance of differences was assessed by ANOVA with the Holm-Šidák or Dunn methods and comparisons were made to the nonirradiated controls. For 2-group comparisons, $t$ tests were used or Mann-Whitney tests if normality tests failed.

\section{RESULTS}

\section{Body Weight After Radiation to Thorax Only}

Nonirradiated animals gained weight in the first week $(2.7 \pm$ $2.4 \mathrm{~g})$, but irradiated rats lost weight $(-1.6 \pm 4.2 \mathrm{~g}, P=0.041$, $n=5$ /group). There was no difference in weight gain or loss between the groups at 2, 3, or $4 \mathrm{wk}$.

\section{Breathing Rate After Radiation}

The respective breathing rates at $1,2,3$, and 4 wk were $99.4 \pm$ $4.3,113.0 \pm 10.4,104.6 \pm 7.9$, and $102.8 \pm 8.9$ breaths $/ \mathrm{min}$ in nonirradiated controls and did not differ from corresponding values after 15 Gy: $103.2 \pm 4.3,108.8 \pm 6.3,108.8 \pm 9.4$, and $98.4 \pm 4.0$ breaths/min ( $n=5 /$ group).

\section{Decrease in Perfused Lung Volume with ${ }^{99 m T c-M A A ~ S P E C T ~}$ After Radiation}

Figure 1 shows representative transaxial slices from the ${ }^{99 \mathrm{~m}} \mathrm{Tc}-$ MAA (left) and ${ }^{99 m}$ Tc-Duramycin (right) reconstructed volume of a nonirradiated control rat (top) and a rat $2 \mathrm{wk}$ after receiving 15 Gy of irradiation (bottom). Fractional perfused lung volume was determined from the ${ }^{99 \mathrm{~m}}$ Tc-MAA images as described in the Materials and Methods section at 1 and 4 wk in nonirradiated controls. Because there was no difference between these groups, they were combined and compared with values obtained at 1, 2, 3, and 4 wk after 15 Gy. Figure 2 shows all values after normalization to 


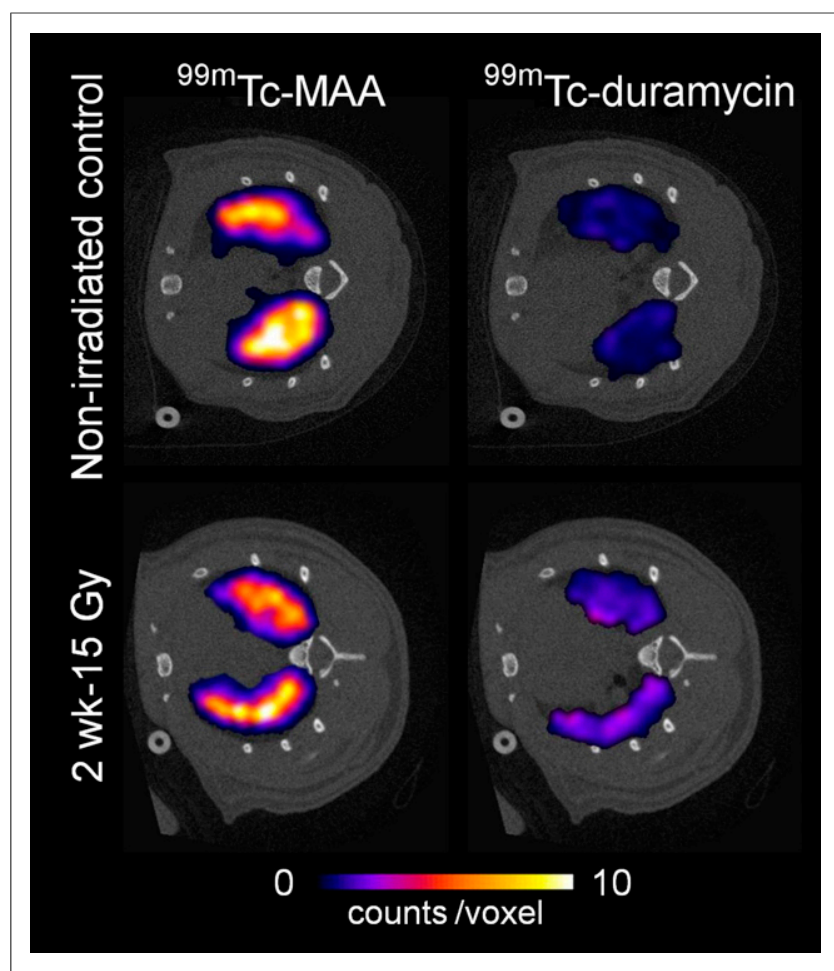

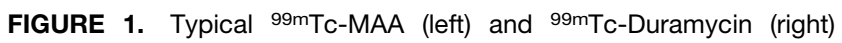
transaxial slices from reconstructed volumes obtained from control (top) and 15-Gy-irradiated (bottom) rats. Color images represent segmented SPECT lung region coregistered with gray-scale CT images.

the median value of the controls. There was a decrease in perfused lung volume starting as early as $1 \mathrm{wk}(18 \%)$ and up to $3 \mathrm{wk}(27 \%)$ after irradiation as compared with nonirradiated controls.

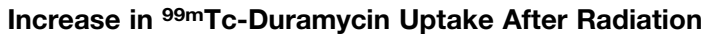

The ${ }^{99 \mathrm{~m}}$ Tc-Duramycin images of Figure 1 reveal very little uptake in the control lung, consistent with our previous results $(16,17)$,

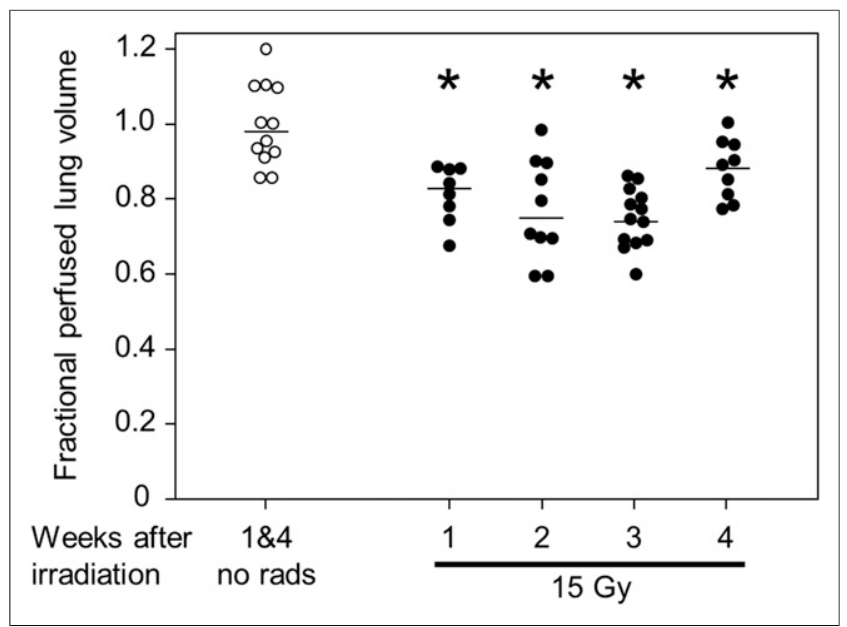

FIGURE 2. Decrease in perfused pulmonary volume by radiation, as determined by ratio of ${ }^{99 \mathrm{mTC}-M A A}$ SPECT perfused volume to coregistered CT anatomic volume. Line is median value in nonirradiated rats (no rads; $n=12)$ and irradiated rats at $1 \mathrm{wk}(n=8), 2 \mathrm{wk}(n=10), 3 \mathrm{wk}(n=13)$, and 4 wk $(n=9)$ after 15 Gy to thorax. ${ }^{*} P<0.05$ vs. nonirradiated controls. but enhanced uptake was seen 2 wk after irradiation. Figure 3 reports average ${ }^{99 \mathrm{~m}} \mathrm{Tc}$-Duramycin counts per voxel within the lung region for each rat. There was no change in ${ }^{99 \mathrm{~m}} \mathrm{Tc}-D u r a m y c i n$ uptake at $1 \mathrm{wk}$ after irradiation but a greater than $100 \%$ increase was observed at 2 and 3 wk compared with nonirradiated controls.

\section{Increase in Apoptotic Cells in Lungs After Radiation}

Figure 4 shows the number of caspase 3-positive apoptotic cells per field in rat lungs. Similar to the ${ }^{99 \mathrm{~m}} \mathrm{Tc}$-Duramycin uptake in Figure 3, there was no increase in apoptotic cells after $1 \mathrm{wk}$ in irradiated rats as compared with nonirradiated controls, but there was an increase in the median number of apoptotic cells per lung field at 2, 3, and $4 \mathrm{wk}$ after irradiation.

\section{Histologic Changes in Lungs at 4 but Not at 1, 2, or 3 Weeks After Radiation}

We measured key histologic markers of radiation injury in nonirradiated and irradiated rat lungs (14,20): vessel wall thickness, alveolar wall thickness, and macrophage counts. The values for these markers did not change in nonirradiated controls at ages corresponding to 1 and $4 \mathrm{wk}$ after irradiation. There was no difference in vessel wall thickness between irradiated rats at 1,2,3, or $4 \mathrm{wk}$ and pooled controls at 1 and $4 \mathrm{wk}$. Although the median score for alveolar wall thickness (Fig. 5D) and macrophage count (Fig. 5E) did not change at 1,2 , or $3 \mathrm{wk}$, both values were higher at $4 \mathrm{wk}$ after $15 \mathrm{~Gy}$ (Figs. $5 \mathrm{D}$ and 5E). Similar results were observed for CD68+ macrophages measured at 2 and 4 wk after 15 Gy (Fig. 5F).

\section{Increase in Pulmonary Vascular Permeability and Resistance at 2 Weeks After Radiation}

We tested the permeability and resistance of lung vessels $2 \mathrm{wk}$ after irradiation, a time point when both ${ }^{99 \mathrm{~m}} \mathrm{Tc}-\mathrm{MAA}$ distribution and ${ }^{99 m}$ Tc-Duramycin uptake were different from nonirradiated controls. Ex vivo pulmonary vascular resistance (Torr $/ \mathrm{mL} / \mathrm{min}$ ) increased from $0.89 \pm 0.14$ in nonirradiated lungs to $1.17 \pm$ 0.19 in irradiated lungs after $2 \mathrm{wk}(n=5, P=0.028)$ (Fig. 6, top). The pulmonary $K_{f}\left(\mathrm{~mL} / \mathrm{min} / \mathrm{cm} \mathrm{H}_{2} \mathrm{O} / \mathrm{g}\right.$ of dry lung weight)

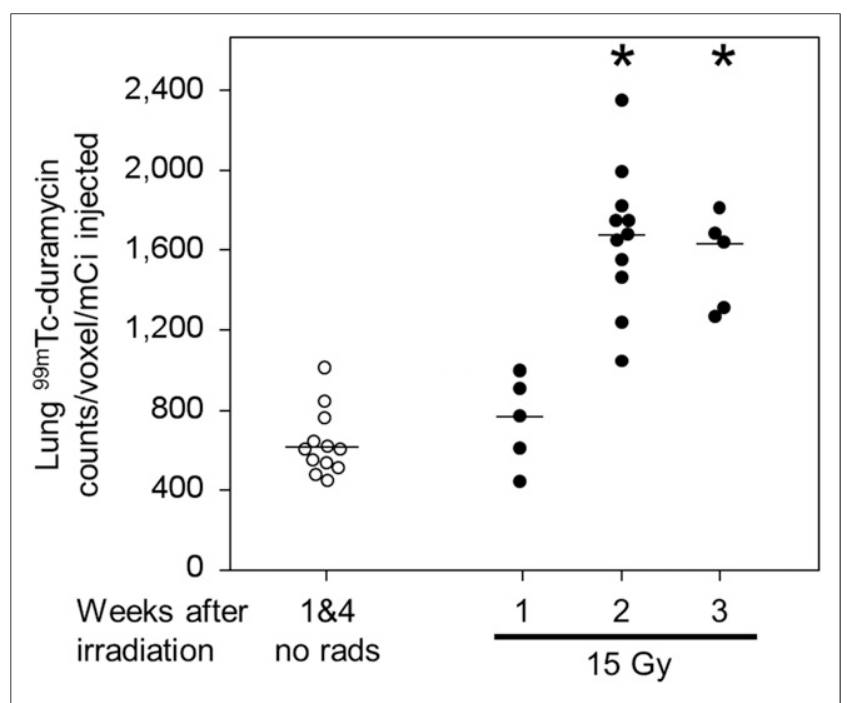

FIGURE 3. Increase in ${ }^{99 m}$ Tc-Duramycin lung uptake in irradiated lungs vs. controls. Line is median value in nonirradiated rats (no rads; $n=12)$ and irradiated rats at $1 \mathrm{wk}(n=5), 2 \mathrm{wk}(n=11)$, and $3 \mathrm{wk}$ $(n=5)$ after 15 Gy to thorax. ${ }^{*} P<0.05$ vs. control. ${ }^{* \star} P<0.05$ vs. 15 Gy at $1 \mathrm{wk}$. 


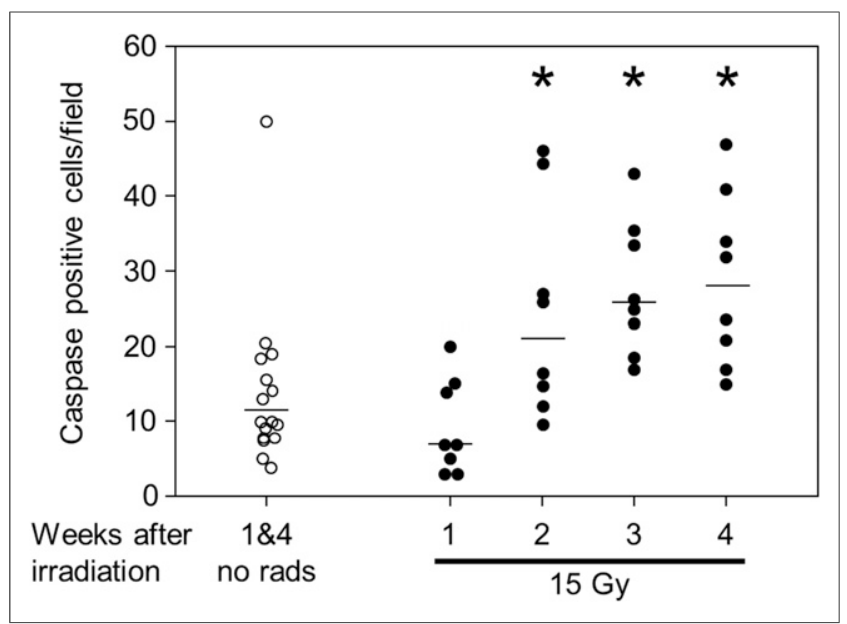

FIGURE 4. Increase in apoptotic cells in lung as determined by cleaved caspase $3+$ cells using immunohistochemistry. Apoptotic cells per field in nonirradiated and irradiated rats are shown at 1, 2, 3, and 4 wk after 15 Gy to thorax. Line is median value in nonirradiated rats (no rads; $n=15$ ) and irradiated rats ( $n=8$ per group). ${ }^{*} P<0.05$ vs. control.

was increased by radiation from $0.017 \pm 0.005$ in nonirradiated lungs to $0.050 \pm 0.010$ in matched irradiated lungs at the 2 -wk time point ( $n=5, P<0.001)$ (Fig. 6 , bottom). The wet-to-dry weight ratio of the perfused lungs showed an increase from $5.9 \pm$ 0.4 in controls to $7.0 \pm 0.2$ after irradiation. The mean \pm SD for the wet weight after perfusion at similar pressures increased from $0.81 \pm 0.07 \mathrm{~g}$ in nonirradiated controls to $1.16 \pm 0.09 \mathrm{~g}$, an increase of $42 \%$.

\section{DISCUSSION}

SPECT has made it possible to develop customized physiologic probes for noninvasive imaging. We have used two probes labeled with ${ }^{99 \mathrm{~m}} \mathrm{Tc}$ to detect radiation-induced preclinical vascular changes and increased apoptosis, two endpoints known to be altered by radiation. Characterization of these changes has the potential to define biomarkers for in vivo detection of radiation injury to the lungs. The first probe, ${ }^{99 m}$ Tc-MAA, with a particle size of 10 $40 \mu \mathrm{m}$, lodges in pulmonary capillaries in proportion to blood flow (18). ${ }^{99 m}$ Tc-MAA is in common clinical use for detection of pulmonary embolism. The second probe is the antibiotic Duramycin, which is a small molecule that binds to apoptotic cells $(9,13)$ and has been labeled with ${ }^{99 \mathrm{~m}} \mathrm{Tc}$ for SPECT imaging $(9,13)$. There was an approximately $20 \%$ decrease in the perfused volume of the lung as early as $1 \mathrm{wk}$ after irradiation with 15 Gy to both lungs, which was sustained for up to $3 \mathrm{wk}$. These data match our observation of increased pulmonary vascular resistance in ex vivo perfused lungs. The uptake of ${ }^{99 \mathrm{~m}} \mathrm{Tc}$-Duramycin in the thorax more than doubled at 2 and 3 wk but was not increased at 1 wk after irradiation. Further studies of ${ }^{99 \mathrm{~m}} \mathrm{Tc}$-Duramycin uptake from only perfused voxels of the lung may determine whether there is a correspondingly higher increase in perfused areas than in the whole lung.

Our data provide strong evidence of preclinical radiationinduced vascular injury in the absence of histologic changes in alveolar wall thickness and macrophage counts. Macrophages (index of inflammatory state) were counted in hematoxylin- and eosin-stained sections, and we confirmed with more specific CD68 staining that they were not increased at $2 \mathrm{wk}$, when perfusion and apoptosis were already altered. Though no increase in vascular wall thickness or occlusion of vascular lumen was noted histologically for up to $4 \mathrm{wk}$, there was an increase in vascular permeability, $K_{f}$, and vascular resistance at $2 \mathrm{wk}$, when measured in irradiated perfused lungs ex vivo. The increase in permeability was also reflected by an increase in wet-to-dry lung weight after perfusion. A dose-dependent increase in vascular permeability at sacrifice has previously been reported after $2 \mathrm{wk}$ in rats exposed to 5-40 Gy to one lung only (25). Molteni et al. also described subendothelial and perivascular edema $1 \mathrm{~d}$ after hemithorax irradiation in rats (26). They reported segmental separation of the endothelium from the basement membrane. In another study, in vivo lung vascular permeability was doubled at $2 \mathrm{wk}$ after whole-thorax irradiation (similar to our results) and peaked to 3 times the normal value by $3 \mathrm{wk}$ (27). Increased permeability in our model may be pathophysiologically related to apoptosis of endothelial cells, as has been reported for other insults (28). These studies by us and others demonstrate that the vasculature in the lungs is injured in the first $4 \mathrm{wk}$ after irradiation to the whole thorax without manifesting clinical symptoms or histologic changes. The results imply that roentgenographic evidence of pulmonary edema in a patient after possible or known radiation exposure could be a prelude to clinical radiation pneumonitis. Such patients may also be good candidates for SPECT imaging to detect endothelial apoptosis.

${ }^{99 m}$ Tc-Duramycin is a recently developed biomarker for SPECT cell death imaging. It has several desirable imaging properties; it binds with very high affinity (the dissociation constant is in the low nanomolar range $(29,30)$ ) and high specificity for membrane-bound
FIGURE 5. Histologic analysis showing increase in alveolar wall thickness and macrophages after 15 Gy of whole-thorax irradiation. Representative fields are shown of hematoxylin- and eosin-stained lung sections from nonirradiated lung (A), lung 2 wk after 15 Gy (B), and lung 4 wk after 15 Gy (C). Solid arrow points to macrophages, dashed arrow to thickened alveolar wall. (D) Scores for alveolar wall thickness. (E) Counts for foamy macrophages. (F) Counts for CD68 ${ }^{+}$ macrophages. Line is median value in nonirradiated rats $(n=16$ each for $D$ and $E$ and 8 for $F)$ and irradiated rats $\left(n=8\right.$ each for D, E, and F). ${ }^{\star} P<0.05$ vs. control at 4 wk. 


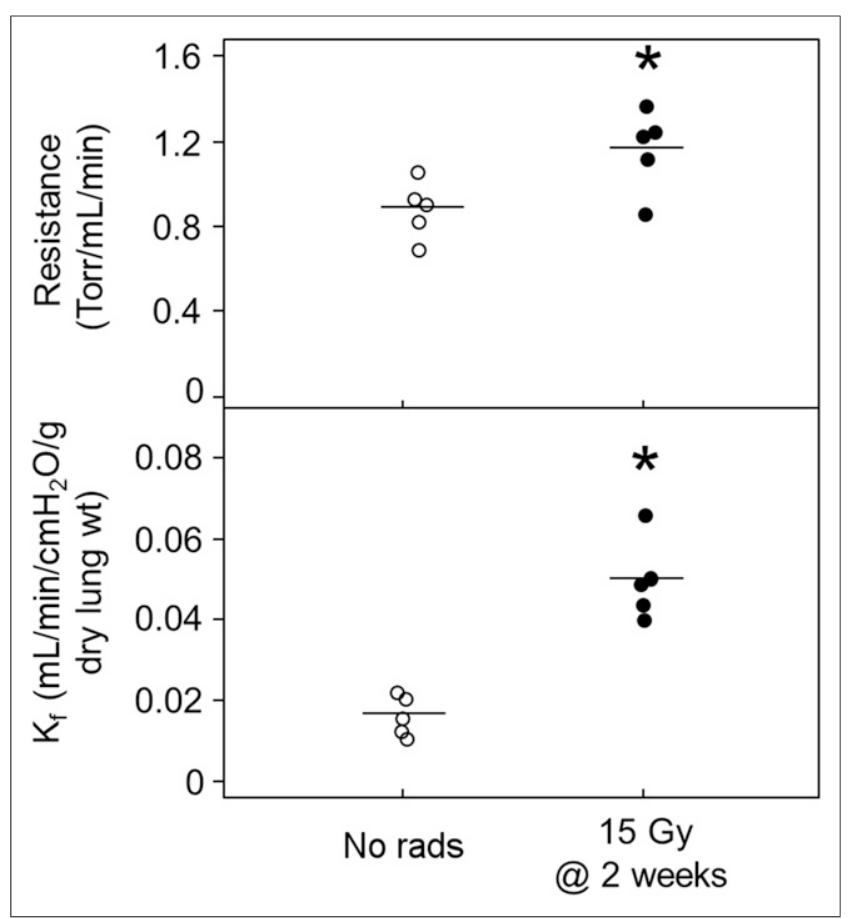

FIGURE 6. Increase in pulmonary vascular resistance and permeability $\left(K_{f}\right)$ in isolated perfused lungs 2 wk after irradiation with 15 Gy. Line is mean value ( $n=5$ rats per group). No rads $=$ nonirradiated rats. ${ }^{*} P<$ 0.05 (top) or $<0.001$ (bottom) vs. control.

phosphatidylethanolamine (31), wherein the binding is stabilized by ionic interaction. Moreover, ${ }^{99 \mathrm{~m}} \mathrm{Tc}$-Duramycin has a low molecular weight $(3,035 \mathrm{~g} / \mathrm{mole})$ and is rapidly cleared from the blood (half-life $<4$ min $(17,32)$ ), thereby keeping background levels low.

In this study, lung uptake of ${ }^{99 \mathrm{~m}} \mathrm{Tc}$-Duramycin was increased $(\sim 160 \%)$ at 2 and 3 wk after irradiation, a finding that was supported by the increase in cleaved caspase $3+$ apoptotic cells. This observation is consistent with a previous study using a hyperoxic lung injury model in which ${ }^{99 \mathrm{~m}} \mathrm{Tc}$-Duramycin lung uptake was shown to correlate strongly with cleaved caspase $3+$ apoptotic endothelial cells (17). Though the increase in vascular permeability could contribute to an increase in ${ }^{99 \mathrm{~m}} \mathrm{Tc}-$ Duramycin lung signal, the high affinity and specificity of binding of ${ }^{99 \mathrm{~m}} \mathrm{Tc}-\mathrm{Duramycin}$ to apoptotic cells, the rapid clearance from the blood, and the increase in cleaved caspase 3 in irradiated rats strongly suggest that the increase in the ${ }^{99 \mathrm{~m}} \mathrm{Tc}-$ Duramycin was due to increased cell death, though further experiments are needed to verify this possibility. Despite these potential limitations, the fact that the increased ${ }^{99 \mathrm{~m}} \mathrm{Tc}$-Duramycin uptake was much higher than the degree of vascular leakage suggests that increased ${ }^{99 \mathrm{~m}} \mathrm{Tc}$-Duramycin uptake may serve as an early biomarker of radiation-induced lung injury.

A small increase in perfusion was recorded 4-6 wk (the earliest time point of the study) after 25 Gy to one lung in Sprague-Dawley rats (7). These measurements were done using $99 \mathrm{~m}$ Tc-MAA and analyzed by comparing perfusion between the irradiated lung and the nonirradiated lung of the same animal. Perfusion in the irradiated lung was lower between 6 and 30 wk (7). A decrease in perfusion to an irradiated lung was recorded in Fischer rats $3 \mathrm{~d}$ after $28 \mathrm{~Gy}$; perfusion recovered by $2 \mathrm{wk}$ and then gradually declined to as low as $15 \%$ by $10 \mathrm{wk}(6)$. Our results are difficult to compare with these studies since we irradiated both lungs and are unique in describing a redistribution of ${ }^{99 \mathrm{~m}} \mathrm{Tc}-\mathrm{MAA}$ from as early as $1 \mathrm{wk}$ and up to at least $3 \mathrm{wk}$ after irradiation. Changes in perfusion distribution may be explained by the changes we measured in vascular resistance. In addition, lung arterioles exhibit decreased ability to constrict or dilate to physiologic stimuli after irradiation $(33,34)$. Such an endpoint cannot be measured in vivo and may contribute to the changes in perfusion we detected by ${ }^{99 \mathrm{~m}} \mathrm{Tc}-$ MAA. Experimentation to test the multiple and known effects of radiation on pulmonary arterioles toward the SPECT signals will take considerable time and resources. Our first goal is to apply our findings to the rapid development of biomarkers for radiation injury to the lungs.

Use of ${ }^{99 \mathrm{~m}} \mathrm{Tc}$-Duramycin for whole-body imaging of irradiationinduced tissue damage has been examined $72 \mathrm{~h}$ after $15 \mathrm{~Gy}$ to the total body of a rat (13). There was increased uptake in the gut, bone, and thymus at this early time. Injury to the lung occurs later (1-3). Our SPECT results using ${ }^{99 \mathrm{~m}}$ Tc-Duramycin suggest ongoing apoptosis in the lung beginning around $2 \mathrm{wk}$ after irradiation and continuing (Fig. 3). The pattern of change in signal was similar in imaging and histology, increasing from 2 wk after irradiation but not at $1 \mathrm{wk}$ (Figs. 3 and 4). These results are important in that they imply patients with possibly injurious exposure could be screened as early as $2 \mathrm{wk}$ after exposure. Those with increased lung apoptosis would be excellent candidates for treatment with agents such as angiotensin-converting enzyme inhibitors, which mitigate lung injury when given up to $5 \mathrm{wk}$ after exposure (3).

\section{CONCLUSION}

Our findings of decreased perfused volume and increased ${ }^{99 \mathrm{~m}} \mathrm{Tc}$-Duramycin uptake in the lungs of irradiated animals are novel and could be developed into new methods of predicting lung injury by radiation even before substantial functional or histologic damage is observed. Further studies with different doses of radiation will determine the specificity for determining lethal lung injury before symptoms develop.

\section{DISCLOSURE}

The costs of publication of this article were defrayed in part by the payment of page charges. Therefore, and solely to indicate this fact, this article is hereby marked "advertisement" in accordance with 18 USC section 1734 . This work was funded by the National Institutes of Health/National Institute of Allergy and Infectious Diseases (1R01AI101898 and U01AI107305-01) and by the National Institutes of Health/National Heart Lung and Blood Institute (HL116530, HL120209, 1I01BX001681, and R15HL129209). No other potential conflict of interest relevant to this article was reported.

\section{ACKNOWLEDGMENTS}

We thank Dr. John E. Moulder for helpful discussions and for critically reading the manuscript. Histologic work was performed by the Pediatric Biobank and Analytic Tissue Core.

\section{REFERENCES}

1. Gross NJ. Radiation pneumonitis in mice: some effects of corticosteroids on mortality and pulmonary physiology. J Clin Invest. 1980;66:504-510.

2. Travis EL, Harley RA, Fenn JO, Klobukowski CJ, Hargrove HB. Pathologic changes in the lung following single and multi-fraction irradiation. Int $J$ Radiat Oncol Biol Phys. 1977;2:475-490. 
3. Gao F, Fish BL, Moulder JE, Jacobs ER, Medhora M. Enalapril mitigates radiationinduced pneumonitis and pulmonary fibrosis if started 35 days after whole-thorax irradiation. Radiat Res. 2013;180:546-552.

4. Robbins ME, Brunso-Bechtold JK, Peiffer AM, Tsien CI, Bailey JE, Marks LB. Imaging radiation-induced normal tissue injury. Radiat Res. 2012;177:449-466.

5. Evans ES, Hahn CA, Kocak Z, Zhou SM, Marks LB. The role of functional imaging in the diagnosis and management of late normal tissue injury. Semin Radiat Oncol. 2007;17:72-80.

6. Fleckenstein K, Zgonjanin L, Chen L, et al. Temporal onset of hypoxia and oxidative stress after pulmonary irradiation. Int J Radiat Oncol Biol Phys. 2007;68:196-204.

7. Ward WF. Radiation-induced pulmonary arterial perfusion defects: modification by D-penicillamine. Radiology. 1981;139:201-204.

8. Boersma LJ, Damen EM, de Boer RW, et al. Recovery of overall and local lung function loss 18 months after irradiation for malignant lymphoma. J Clin Oncol. 1996;14:1431-1441.

9. Zhao M, Li Z. A single-step kit formulation for the ${ }^{99 \mathrm{~m}} \mathrm{Tc}$-labeling of HYNICDuramycin. Nucl Med Biol. 2012;39:1006-1011.

10. Verheij M, Bartelink H. Radiation-induced apoptosis. Cell Tissue Res. 2000;301: $133-142$.

11. Holcik M, Yeh C, Korneluk RG, Chow T. Translational upregulation of X-linked inhibitor of apoptosis (XIAP) increases resistance to radiation induced cell death. Oncogene. 2000;19:4174-4177.

12. Garcia-Barros M, Paris F, Cordon-Cardo C, et al. Tumor response to radiotherapy regulated by endothelial cell apoptosis. Science. 2003;300:1155-1159.

13. Johnson SE, Li Z, Liu Y, Moulder JE, Zhao M. Whole-body imaging of highdose ionizing irradiation-induced tissue injuries using ${ }^{99 \mathrm{~m}} \mathrm{Tc}$-duramycin. $\mathrm{J} \mathrm{Nucl}$ Med. 2013;54:1397-1403.

14. Medhora M, Gao F, Glisch C, et al. Whole-thorax irradiation induces hypoxic respiratory failure, pleural effusions and cardiac remodeling. J Radiat Res (Tokyo). 2015;56:248-260.

15. Medhora M, Gao F, Fish BL, Jacobs ER, Moulder JE, Szabo A. Dose-modifying factor for captopril for mitigation of radiation injury to normal lung. J Radiat Res (Tokyo). 2012;53:633-640.

16. Clough AV, Audi SH, Haworth ST, Roerig DL. Differential lung uptake of ${ }^{99 \mathrm{~m}} \mathrm{Tc}$-hexamethylpropyleneamine oxime and ${ }^{99 \mathrm{~m}} \mathrm{Tc}$-duramycin in the chronic hyperoxia rat model. J Nucl Med. 2012;53:1984-1991.

17. Audi SH, Jacobs ER, Zhao M, Roerig DL, Haworth ST, Clough AV. In vivo detection of hyperoxia-induced pulmonary endothelial cell death using ${ }^{99 \mathrm{~m}} \mathrm{Tc}$-duramycin. Nucl Med Biol. 2015;42:46-52.

18. Wietholt C, Roerig DL, Gordon JB, Haworth ST, Molthen RC, Clough AV. Bronchial circulation angiogenesis in the rat quantified with SPECT and microCT. Eur J Nucl Med Mol Imaging. 2008;35:1124-1132.

19. Audi SH, Roerig DL, Haworth ST, Clough AV. Role of glutathione in lung retention of ${ }^{99 \mathrm{~m}} \mathrm{Tc}$-hexamethylpropyleneamine oxime in two unique rat models of hyperoxic lung injury. J Appl Physiol. 2012;113:658-665.
20. Gao F, Fish BL, Szabo A, et al. Short-term treatment with a SOD/catalase mimetic, EUK-207, mitigates pneumonitis and fibrosis after single-dose totalbody or whole-thoracic irradiation. Radiat Res. 2012;178:468-480.

21. Gan Z, Roerig DL, Clough AV, Audi SH. Differential responses of targeted lung redox enzymes to rat exposure to 60 or $85 \%$ oxygen. $J$ Appl Physiol. 2011;111: 95-107.

22. Bongard RD, Yan K, Hoffmann RG, et al. Depleted energy charge and increased pulmonary endothelial permeability induced by mitochondrial complex I inhibition are mitigated by coenzyme Q1 in the isolated perfused rat lung. Free Radic Biol Med. 2013;65:1455-1463.

23. Srinivasan A, Roth KA, Sayers RO, et al. In situ immunodetection of activated caspase-3 in apoptotic neurons in the developing nervous system. Cell Death Differ: 1998;5:1004-1016.

24. Gao F, Narayanan J, Joneikis C, et al. Enalapril mitigates focal alveolar lesions, a histological marker of late pulmonary injury by radiation to the lung. Radiat Res. 2013; 179:465-474.

25. Travis EL, Hargrove H, Klobukowski CJ, Fenn JO, Frey GD. Alterations in vascular permeability following irradiation. Radiat Res. 1976;67:539.

26. Molteni A, Wolfe LF, Ward WF, et al. Effect of an angiotensin II receptor blocker and two angiotensin converting enzyme inhibitors on transforming growth factor-beta (TGF-beta) and alpha-actomyosin (alpha SMA), important mediators of radiation-induced pneumopathy and lung fibrosis. Curr Pharm Des. 2007;13:1307-1316.

27. Graham MM, Evans ML, Dahlen DD, Mahler PA, Rasey JS. Pharmacological alteration of the lung vascular response to radiation. Int J Radiat Oncol Biol Phys. 1990;19:329-339.

28. Lu Q, Xu DZ, Davidson MT, Hasko G, Deitch EA. Hemorrhagic shock induces endothelial cell apoptosis, which is mediated by factors contained in mesenteric lymph. Crit Care Med. 2004;32:2464-2470.

29. Hayashi F, Nagashima K, Terui Y, Kawamura Y, Matsumoto K, Itazaki H. The structure of PA48009: the revised structure of duramycin. J Antibiot (Tokyo). 1990;43:1421-1430.

30. Zimmermann N, Freund S, Fredenhagen A, Jung G. Solution structures of the lantibiotics Duramycin B and C. Eur J Biochem. 1993;216:419-428.

31. Zhao M. Lantibiotics as probes for phosphatidylethanolamine. Amino Acids. 2011;41:1071-1079.

32. Zhao M, Li Z, Bugenhagen S. ${ }^{99 \mathrm{~m}} \mathrm{Tc}-$ labeled duramycin as a novel phosphatidylethanolamine-binding molecular probe. J Nucl Med. 2008;49:13451352 .

33. Zhang R, Ghosh SN, Zhu D, et al. Structural and functional alterations in the rat lung following whole thoracic irradiation with moderate doses: injury and recovery. Int J Radiat Biol. 2008;84:487-497.

34. Ghosh SN, Zhang R, Fish BL, et al. Renin-angiotensin system suppression mitigates experimental radiation pneumonitis. Int J Radiat Oncol Biol Phys. 2009;75:1528-1536. 